\title{
Structural and Morphological Investigations on Shape Memory CuZnAl Alloys
}

\author{
R. ZENGIN AND N. KAYAL \\ Faculty of Education, Division of Science Teaching, University of Firat, 23169 Elazig, Turkey
}

(Received March 9, 2010; in final form May 28, 2010)

\begin{abstract}
Macroscopic, structural and morphological features of shape memory CuZnAl alloys were examined by elongation parameter measurement, X-ray diffraction and optical metallography. It has been seen that shape initiating temperature $\left(T_{z}\right)$ is greater than austenite start temperature $\left(A_{\mathrm{s}}\right)$. According to the X-ray diffraction, it has been defined that transformation happened from austenite phase to martensite phase as $L 2_{1} \rightarrow M 18 R$ and martensite crystal lattice has been in monoclinic structure. In metallographic observations the grain structures were observed, then plate martensites, V-type martensite structures, twin-like bands, precipitation phases were found. In addition, it has been observed that $\alpha$-sediment phase has occurred in specimens with ageing at austenitic phase condition.
\end{abstract}

PACS numbers: $62.20 . \mathrm{fg}$

\section{Introduction}

Martensitic transformation is a kind of first-order transition observed in some metals and alloys. The martensitic transformation in copper-based alloys is thermoelastic, that is, the transformation progresses following the undercooling below the equilibrium temperature. In addition, a hysteresis is observed because of irreversible processes taking place during the transformation-retransformation path [1-3]. The martensitic phases can be either thermally-induced, spontaneous transformation, or stress-induced, cooling or stressing the $\beta$ phase. Because of the non-diffusive character of the transformation the martensite inherits the atomic order from the $\beta$ phase [4].

Reversible shape memory alloys have become the source of considerable technological interest as a result of their ability to generate spontaneous changes of shape on thermal cycling, because the substantial recovery stresses generated during the martensite-to-parent transformation on heating can convert heat directly into mechanical work $[5,6]$. In particular, shape memory actuators are extensively used as a component in various devices [7]. Shape memory alloys are metastable in martensitic condition and affected by the thermal cycling as well as by ageing at product and parent phase conditions.

In the present study, the elongation parameters of reversible shape-memory two $\mathrm{CuZnAl}$ alloy actuators (helical springs) are reported as a function of temperature. The changes at the elongation against temperature in the existence of an external strain are examined. Crystal structure and lattice parameters were determined by means of X-ray diffraction for alloys. In addition, the morphological properties of both quenched and annealed specimens with different durations at an intermediate temperature, $200^{\circ} \mathrm{C}$, are investigated.

\section{Experimental procedure}

Two shape memory actuators of CuZnAl alloy were supplied by Delta Materials Research Ltd., Ipswich, England. These alloys received in the closed-coil form called shape memory actuator have originally open-coil form in austenitic condition and they have been given the closed-coil form deforming in martensitic condition. These alloys were labeled alloy 1 and alloy 2 . Alloy 1 with a nominal composition $\mathrm{Cu}-24.98 \mathrm{Zn}-4.43 \mathrm{Al}$ and alloy 2 with a nominal composition $\mathrm{Cu}-21.62 \mathrm{Zn}-5.68 \mathrm{Al}$ (in wtand $e / a$ ratio of each one is 1.4286 and 1.4462 , respectively.

The shape memory actuators were mounted on a coaxial scaled rod. So that one end is fixed and the other free. Traditional steel actuators of which one end was fixed with different actuators fixing was mounted above these in order to create cyclic conditions on the shape memory equipments. With the help of this mechanism, elongation parameters $(\delta)$ of alloy actuators were obtained as the function of temperature for heating cycles.

Powder specimens for X-ray examinations were prepared by filing the alloys. These specimens were then solution treated in evacuated quartz tubes in the $\beta$ phase field (for $20 \mathrm{~min}$ at $820^{\circ} \mathrm{C}$ ), and immediately quenched in iced brine to obtain $\beta$-type martensite. The $\mathrm{X}$-ray profiles were taken by using Philips PW 1050 X-ray diffractometer. For these examinations, Co $K_{\alpha}$ radiation with wavelength $1.7902 \AA$ was used, and the scanning rate 
of the Geiger counter was chosen as $2^{\circ}, 2 \theta / \mathrm{min}$ for the profiles.

For the metallographic investigations, the specimens have been solution treated in the $\beta$-phase condition $\left(820^{\circ} \mathrm{C}\right.$ for $\left.20 \mathrm{~min}\right)$ for homogenization and quenched in iced-brine to remain the $\beta$-phase. These specimens have been aged in the austenitic condition $200^{\circ} \mathrm{C}$ for up to $8 \mathrm{~h}$ : all specimens were mechanically polished and etched by a solution of $5 \mathrm{~g}$ ferric chloride, $96 \mathrm{ml}$ methanol and $20 \mathrm{ml}$ concentrate $\mathrm{HCl}$. In order to obtain the surface morphology after ageing in the austenitic condition, metallographic observations were carried out using a Reichert MeF2 optical microscope.

\section{Results and discussion}

Figure 1a and b show heating curves of the elongation parameter $(\delta)$ for heating cycle in case of free and applied different outer actuator stresses for actuators of alloy 1 and 2 . The initiation temperature $\left(T_{z}\right)$ of macroscopical shape change and the completion temperature were obtained as 41.5 and $53^{\circ} \mathrm{C}$, respectively for alloy 1 , whilst these temperatures were 36 and $47^{\circ} \mathrm{C}$ for alloy 2 . The differences between the initiation and completion temperatures of the shape changes are 11.5 and $11^{\circ} \mathrm{C}$ for alloys 1 and 2, respectively; and these results are close matching with the literature because $\mathrm{CuZnAl}$ alloys have a transformation hysteresis of about $10^{\circ} \mathrm{C}$ [8-11].

According to Fig. 1a, $T_{z}$ temperature for alloy 1 is $k=0,0.15,1.25$ and $3.8 \mathrm{~N} / \mathrm{mm}$, for outer spring constant is $41.5,41.5,44$ and $44.5^{\circ} \mathrm{C}$, temperatures in which shape change is completed are $53,54,55.5$ and $58^{\circ} \mathrm{C}$. On the other hand, according to Fig. $2 \mathrm{~b}, T_{z}$ temperature of alloy 2 for the same spring constant is $36.5,36.5,37$ and $38.5^{\circ} \mathrm{C}$, whereas the temperatures in which opening is completed are determined as $47,49.5,50.5$ and $54^{\circ} \mathrm{C}$. As a result while 3 and $2{ }^{\circ} \mathrm{C}$ increases can be seen in $T_{z}$ temperature of alloy 1 and 2 for $k=3.8 \mathrm{~N} / \mathrm{mm}, 5$ and $7{ }^{\circ} \mathrm{C}$ increases can be observed in the temperatures in which opening is completed. That is it was seen that opposite force applied by the used outer actuator is especially effective at high temperatures.

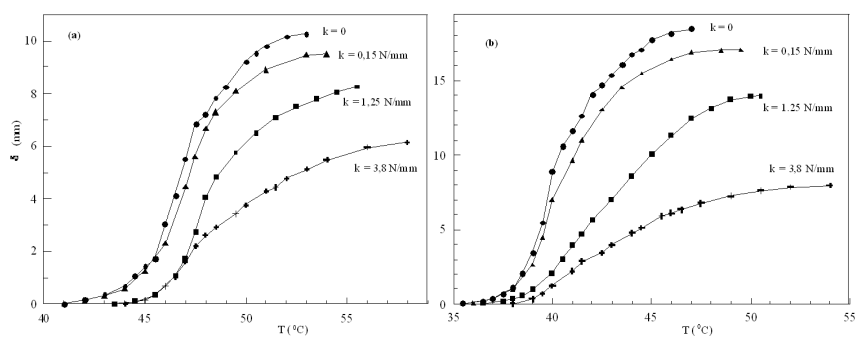

Fig. 1. Variation of the elongation parameter for heating cycle in case of free and different outer actuator stresses for actuators of: (a) alloy 1, (b) alloy 2.

Alloy 1 spring parameter $\delta$ was measured as 10.25, $9.5,8.25$ and $6.15 \mathrm{~mm}$ in order at outer spring stress of $k=0,0.15,1.25$ and $3.8 \mathrm{~N} / \mathrm{mm}$, while $17.46,16.08,14$ and $7.95 \mathrm{~mm}$ for alloy 2 spring parameter. Hence, it was concluded that alloy 2 spring is exposed to a more serious deformation at martensitic conditions and produced mechanic force is greater. According to these results, with the increase of outer spring constant a decrease in stage can be seen at $\delta$ elongation parameter. Elongation parameter of alloy 1 and 2 actuators decreased $40 \%$ and $57 \%$ for $k=3.8 \mathrm{~N} / \mathrm{mm}$ outer spring constant. That is, some part of the force obtained by the elongation of alloy actuators during martensite $\rightarrow$ austenite transformation is used for defeating outer spring stress rising with heating. From these results it can be said that considerable losses could be observed at shape recovery rates, an important parameter of alloy actuators, if the outer spring was applied.

Typical powder diffractograms obtained from as-quenched specimens of alloy 1 and alloy 2 martensites are shown in Fig. 2a and $\mathrm{b}$ with indexed peaks, respectively. The lattice parameters obtained from these diffractograms for as-quenched specimens of alloy 1 and alloy 2 as calculated are, respectively, $a=4.4153 \AA, b=$ $5.3344 \AA, c=38.2076 \AA$ and $\beta=88.5856^{\circ} ; a=4.4728 \AA$, $b=5.3276 \AA, c=38.2005 \AA$, and $\beta=89.1166^{\circ}$.

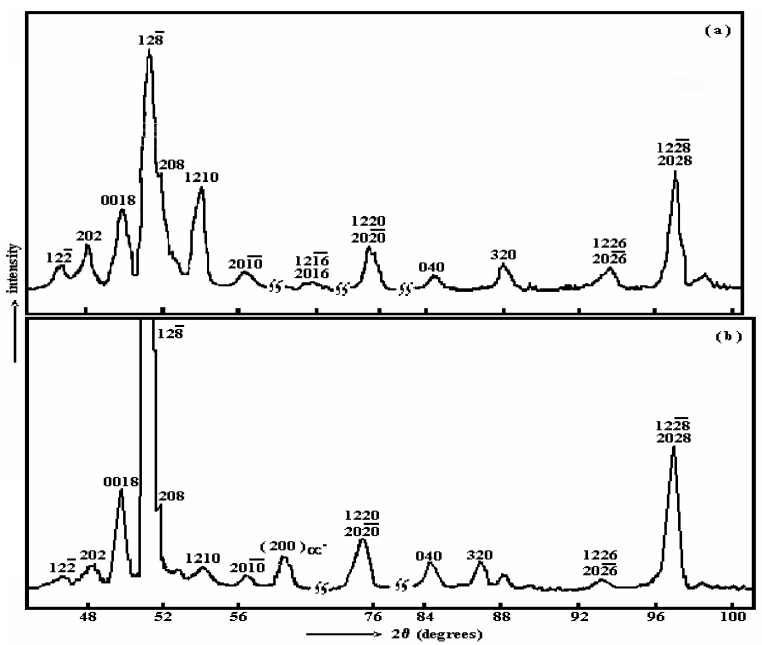

Fig. 2. X-ray powder diffractograms of quenched samples of (a) alloy 1 and (b) alloy 2 .

According to the lattice parameters calculated from the profiles in Fig. 2, transformation from austenite phase to martensite phase emerges as $L 2_{1} \rightarrow M 18 R, a / b$ rate of lattice parameters was calculated as 0.8277 and 0.8396 for alloy 1 and 2 in order and it is lower than ideal 0.8660 . It was thought that the reason of this may be the asymmetrical forces which affect atomic position because of the ordered sequence on the tight-packet plane. Regarding this we can reach a conclusion that crystal martensite lattice structure arising from the main phase is order, in which the atoms in the main phase are placed on the lattice and basal plane consists of the atoms of different sizes. 
According to the lattice parameters given above a lattice parameter of alloy 2 with more aluminum in it is greater than a lattice parameter of alloy 1 . Considering this, the greatness of $\mathrm{Al}$ concentration leads to a wideness along $x$-axis. From this, decrease in a symmetrical force affects atomic positions, so a decrease in monoclinic distortion and an increase at $\beta$ monoclinic angle is expected. These interpretations are supported having greater $\beta$ angle of alloy 1 according to the valences of $\beta$ angle for alloy 1 and 2 as $88.5856^{\circ}$ and $89.1156^{\circ}$.

Figure $3 \mathrm{a}$ shows the optic micrograph indicating the grain structure of alloy 1 sample aged at $200^{\circ} \mathrm{C}$ for $1 \mathrm{~h}$ after quenching. There have been 3 grains and plate tendencies show differences even in the same grain. The structures marked by short arrows in the subgrain are defined as plate martensites [11]. The grain size of lower side of figure was measured as $350 \mu \mathrm{m}$. The structures marked by long arrows in the same grain are defined as V-type martensite plates $[12,13]$. It has been observed that martensite plates continue to there at grains or grain boundary and they cannot pass to another grain. In addition, orientation seen at left-lower plate can be dependent on the cooling difficulties happening from great temperature difference.

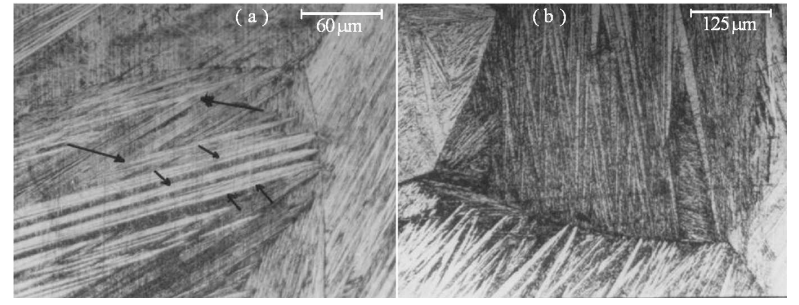

Fig. 3. (a) The grain structure of alloy 1 sample aged for $1 \mathrm{~h}$ at $200^{\circ} \mathrm{C}$ after quenching, (b) the grain structure and martensite morphology of alloy 2 sample after quenching.

Figure 3b shows the martensite morphology and grain structure for alloy 2 specimen after directly quenched from betatizing temperature $\left(820^{\circ} \mathrm{C}\right)$. The plates seen at the lower grain are sharp, these plates are being known as V-type martensite plates. On the other hand, these plates at middle grain are not sharp: this situation can be caused by the inner stresses occurring at austenitemartensite phase boundary during the forming of plates. The grain size of middle grain of the figure was measured as $460 \mu \mathrm{m}$.

The plate structure of alloy 1 aged for $1 \mathrm{~h}$ at $200^{\circ} \mathrm{C}$ after quenching is shown in Fig. 4a. The upper side of Fig. 4a shows the V-type self-accommodating growth with four variants contained in a plate group [12-14]. As indicated by long arrows, parallel bands on plates in the middle and V-typed some plates of Fig. 4a are defined as lamellar martensite or twin-like morphology [15]. Inner bindings parallel to the martensite basal plane are also on these bands because of $18 R$ twin layers or defects. Not being observed of the substructure in these twin-like or banded structures can be expressed that these have the single crystal area having some defects on the basal plane [13]. Band thick and band interval of these structures are measured as about 1.3 and $1 \mu \mathrm{m}$, respectively. Martensite structures marked with short arrows under micrograph are defined as needle martensite in literature. Needle martensite morphology forms with the injection of strange variants because of other plate groups [13].

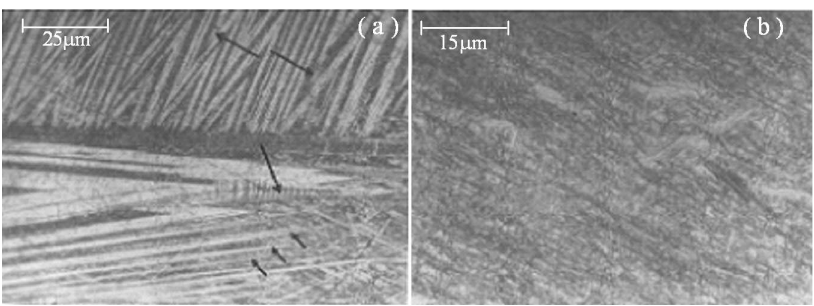

Fig. 4. (a) The typical martensite morphology of alloy 1 sample aged for $1 \mathrm{~h}$ and $200^{\circ} \mathrm{C}$ after quenching, (b) the dense $\alpha$-phase sediments forming in alloy 1 sample aged for $7 \mathrm{~h}$ at $200{ }^{\circ} \mathrm{C}$ after quenching.

Figure $4 \mathrm{~b}$ shows the dense $\alpha$-phase sediments forming in alloy 1 sample aged for $7 \mathrm{~h}$ at $200{ }^{\circ} \mathrm{C}$ after cooling at water and homogenizing. It has been understood that this phase forms with the aging effect in the austenite phase area at $200{ }^{\circ} \mathrm{C}$, and its density increases with aging period. Because transformations emerging with aging diffusion transfer effectively with vacancy concentration, they change the chemical concentration. As pointed out by Shuchuan et al. [16], $a$-phase precipitates partially by heating to over $120^{\circ} \mathrm{C}$ and intensively over $240{ }^{\circ} \mathrm{C}$ in $\mathrm{CuZnAl}$ alloys. One can say from these results that the formation of $\alpha$ or other precipitates causes the decrease of the transformation temperature by preventing martensite formation, and important losses of the shape-memory capacity. This effect is related to the interaction of martensite interfaces with precipitates and defects.

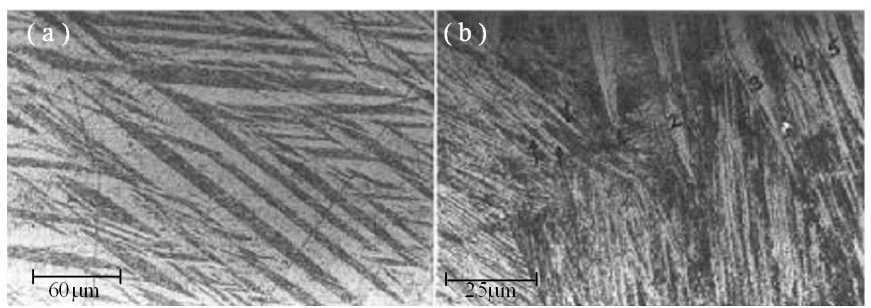

Fig. 5. (a) The typical martensite plate groups in alloy 2 after quenching, (b) subgrain structures and fine martensites in alloy 2 sample aged for $4 \mathrm{~h}$ at $200{ }^{\circ} \mathrm{C}$ after quenching.

Figure 5a shows the structure defined as diamond-like configuration or martensite plate groups harmonously with each other observed in alloy 2 sample cooled in water. Thermoelastic transformation, responsible for shape memory mechanism, begins to form in morphology harmoniously with each other, consisting of zigzag plates 
of half-decided $\beta_{3}$ martensite at $M_{\mathrm{s}}$ temperature, and martensite formation is completed at $T<M_{\mathrm{f}}$ temperature. When the reason of this formation is compared with $\beta$ phase, lower symmetry of martensite structure leads to the formation of many martensite plate variants having a lot of different tendencies in a $\beta$ phase grain. These kinds of structure are characterised with 6 variant groups consisting of 4 different single-crystal each of which directed differently [12-17].

Figure 5b shows the micrograph taken from alloy 2 sample aged for $4 \mathrm{~h}$ at $200^{\circ} \mathrm{C}$. Detailed investigations confirm that this sample contains a lot of small subgrains directed with narrow angles. The parts marked with 1-5 on the right of the photograph show this feature. 3 number sub-grain is directed by a wider angle considering $1,2,4,5$ number sub-grains. Bending angles occurring during the transfer of martensite plates to a sub-grain are harmonious with $10-20^{\circ}$ deviation angles given in literature [14-18]. It has been known that sub-grain is smaller than $\beta$-phase grains and they are $50 \mu \mathrm{m}$ [15]. Morphologies marked with short arrows in Fig. 5b micrograph are defined as parallel-sided and fine ribbon needle martensites. Furthermore, these finely striated plates can only grow in one dimension, i.e., in a direction perpendicular to parent-martensite interfaces, whereas $\beta$ grains grow three-dimensionally [13] and it is expected that the number of martensite plates nucleated in a quenched shape memory alloy is directly proportional to the concentration of the defects in which exists in $\beta$-phase at the quenching time. But fine and parallel plates observed intensively in middle grain have virtually one direction [11].

\section{Conclusions}

1. It has been found that outer actuators apply a force increasing with the heating on alloy springs. Elongation parameter of alloy 1 and 2 actuators decreased $40 \%$ and $57 \%$ for $k=3.8 \mathrm{~N} / \mathrm{mm}$ outer spring constant.

2. The transformation from the $\beta$ phase to martensite phase for the $\mathrm{CuZnAl}$ alloys are realized as $L 2_{1} \rightarrow$ $M 18 R$ transition.

3. A number of randomly distributed vacancies do not affect ordering, and ordering degree closely depends on the alloy composition, quenching rate and post-quench heat treatments.

4. The intensive $\alpha$-phase precipitates occurring in the specimens aged up to $7 \mathrm{~h}$ in the $\beta$-phase $\left(200^{\circ} \mathrm{C}\right)$ cause deterioration of the shape-memory capacity or life.
5 . It has been observed that $\beta$-grains grew three-dimensionally whilst the finely or parallel-sided martensite plate have virtually grown in one dimension.

\section{Acknowledgments}

The author would like to thank Dr. Nejdet Kayali for help with experimental management and assistance.

\section{References}

[1] K. Otsuka, K. Shimizu, Int. Metals Rev. 31, 93 (1986).

[2] D.W. Roh, E.S. Lee, Y.G. Kim, Metall. Mater. Trans. A 23, 2753 (1992).

[3] N. Haberkorn, F.C. Lovey, A.M. Condó, J. Guimpel, Mater. Sci. Eng. B 170, 5 (2010).

[4] T. Saburi, S. Nenno, S. Kato, K. Takata, J. Less Common Metals 50, 223 (1976).

[5] G. Guénin, in: Proc. Europ. Conf. on Martensitic Transformation in Science and Technology, Eds. E. Hornbogen, N. Jost, DGM Inf. Verlag, Oberursel, Germany, 1989, p. 39 .

[6] R. Stalmans, J.V. Humbeeck, L. Delaey, Acta Metall. Mater. 40, 2921 (1992).

[7] J. Loughlan, S.P. Thompson, H. Smith, Composite Struct. 58, 319 (2002).

[8] C.M. Friend, Scr. Metall. 20, 995 (1986).

[9] V. Dia, L.G. Bujoreanu, S. Stanciu, C. Munteanu, Mater. Sci. Eng. A 481, 697 (2008).

[10] P. Tautzenberger, G. Rau, et al. in: Proc. Europ. Conf. on Martensitic Transformation in Science and Technology, Eds. E. Hornbogen, N. Jost, DGM Inf. Verlag, Oberursel, Germany, 1989, p. 213.

[11] N. Kayalı, S. Özgen, O. Adıgüzel, J. Mater. Proc. Technol. 101, 245 (2000).

[12] N. Kayalı, S. Özgen, O. Adıgüzel, Mater. Res. Bull. 32, 569 (1997).

[13] K. Adachi, J. Perkins, Metall. Mater. Trans. A 17, 945 (1986).

[14] N. Kayalı, R. Zengin, O. Adıgüzel, Metall. Mater. Trans. A 31, 349 (2000).

[15] Z. Nishiyama, Martensitic Transformation, Academic Press, New York 1978, p. 115.

[16] C. Shuchuan, T.Y. Hsu, Y. Fan, Z. Jihau, in: Proc. ICOMAT '92, Ed. J. Perkins, Monterey Institute for Advanced Studies, Monterey, USA 1992, p. 599.

[17] A.K. Bhuniya, P.P. Chattopadhyay, S. Datta, M.K. Banerjee, Mater. Sci. Eng. A 391, 34 (2005).

[18] Y. Xu, S. Shimizu, et al. Acta Mater. 45, 1503 (1997). 